\title{
HERMENÊUTICA E TEORIA CRÍTICA: ILUMINISMO COMO POLÍTICA ${ }^{1}$
}

Dick HOWARD 2

- RESUMO: O presente artigo, analisando a hermenêutica de Gadamer e a teoria crítica de Horkheimer e Marcuse, procura mostrar que, se se concebe a sociedade moderna do ponto de vista do político, é possivel elaborar uma teoria da modernidade em que ambas, em vez de se oporem, sejam complementares.

- PALAVRAS-CHAVE: Hermenêutica; teoria crítica; política; sociedade civil; modernidade.

\section{O problema: fundando a política}

Numa carta publicada como apêndice a Beyond objectivism and relativism, de Richard Bernstein, Gadamer descreve a diferença central entre ele e Habermas como política. Obviamente, "política" aqui não se refere às Weltanschauungen ou à política partidária; refere-se antes a diferentes concepções do papel prático da filosofia. Segundo a descrição de Gadamer, Bernstein e Habermas negam que sociedades verdadeiramente modernas partilhem o Ethos comum ou comunidade de consciência normativa que fundamentava a transição aristotélica da Ética para a Política. Em vez disso, as condições modernas exigiriam a passagem da filosofia prática para a ciência social. Gadamer rejeita a hybris dessa alegação; ele insiste que as solidariedades sociais existem e que não estamos vivendo numa sociedade "constituída apenas por engenheiros sociais ou tiranos. "Platão", continua, "viu isto muito bem: não há cidade tão corrompida que não realize algo da verdadeira cidade". Este "algo" compartilhado pela comunidade fundamenta a phronesis, que é a forma filosoficamente adequada de prática (Bernstein, 1983, p. 264). A questão é sobre como estabelecer a demonstração da sua presença ou ausência.

1. Artigo publicado com o título de "Enlightment as political", in Welton and Silverman, Critical and dialectical phenomenology, Albany: SUNY Press, 1987, p. 76-89. A tradução é da autoria de Marcos Barbosa de Oliveira e Isabel Maria Loureiro.

2. Professor de filosofia na State University of Nova York - 11794-3750 - Stony Brook - NY.

3. Carta escrita em 1.7.1982. Apêndice a Richard Bernstein, 1983, p. 262. 
O livro de Bernstein consiste num esforço notável para juntar diferentes fios da filosofia contemporânea em torno da estrutura de uma modernidade por ele sintetizada como "angústia cartesiana". O leitor familiarizado com a "teoria crítica", elaborada pela primeira geração da Escola de Frankfurt, reconhecerá no estudo de Bernstein a tentativa de fundar de forma imanente a distinção entre teoria tradicional e teoria crítica, que culminou no artigo de mesmo título escrito por Max Horkheimer em 1937. Embora o método de Horkheimer seja diferente do de Bernstein, seus objetivos "políticos" são os mesmos: nas palavras de Bernstein, mesmo sem compartilhar "a certeza teórica ou a autoconfiança revolucionária de Marx", eles consistem em "nos dedicarmos à tarefa prática de promover o tipo de solidariedade, participação e reconhecimento mútuo" que, de fato, "nos levará para além do objetivismo e do relativismo" (p. 231). Infelizmente, nem Horkheimer nem Bernstein conseguiram fundamentar este imperativo político como imperativo filosófico.

Seria equivocado opor a teoria crítica à teoria hermenêutica, como se a primeira fosse resolutamente "moderna", e o apelo da última à autoridade ou ao "preconceito", uma fundamentação irracional, externa e, em última análise, tradicional. A resposta de Gadamer (1975, p. 258-9) a esta crítica refere-se explicitamente à Dialética do Iluminismo, de Adorno e Horkheimer, assim como à Histónia e consciência de classe, de Lukács. ${ }^{4}$ Ele tenta mostrar o caráter especificamente histórico de uma hermenêutica filosoficamente fundamentada, indo além das ingenuidades do historicismo do século XIX.

O pensamento verdadeiramente histórico precisa pensar simultaneamente a sua própria historicidade... O verdadeiro objeto histórico não é objeto algum; é ... uma relação na qual a atualidade da história, tanto quanto a atualidade da compreensão histórica estão co-presentes. Uma hermenêutica adequada teria que demonstrar a atualidade da história em entender-se a si mesma. (p. 283)

Esta imanência da compreensão histórica e do objeto historicamente dado recusa-se a apelar para normas externas para explicar quer a gênese, quer a validade do conhecimento hermenêutico. Isto deixa o filósofo perante a necessidade de fundamentar seus argumentos. ${ }^{5}$ A dificuldade é que refutar a alegação de que a hermenêutica é pré-moderna é feita no sentido de tornar explícito um dilema teórico que a definição de hermenêutica como "ontologia" tende a ocultar. A hermenêutica

4. Gadamer, rejeitando implicitamente a noção de razão instrumental a que voltaremos depois, critica Horkheimer e Adorno por estenderem a noção de iluminismo até a Odisséia.

5. A hermenêutica moderna, que se exclui da "filosofia da consciência" típica do historicismo, da Einfühlungsphilosophie diltheyana, ou do Verstehen metodológico, faz da necessidade, virtude - ela literalmente ontologiza suas próprias dificuldades. Explica que não podemos pôr a questão dos fundamentos porque esses fundamentos fundamentam nosso próprıo ser-como-questionador. Não podemos pôr a questão do começo porque sempre já teremos começado. Quer o circulo hermenêutico seja concebido ontologicamente como em Gadamer, quer linguisticamente como em Apel, o dilema permanece. A filosofia não pode eliminar a questão dos fundamentos sem correr o risco de ser acusada de irracional. Mas uma filosofia moderna não pode invocar fundamentos cujo caráter normativo não possa justificar imanentemente. 
de Gadamer, assim como a política da teoria crítica, precisam ser filosoficamente fundamentadas.

Do ponto de vista da teoria política, a descrição de Gadamer de uma "hermenêutica adequada (sachgemessene)" lembra a insistência de Hegel (1970, p. 83) em que a verdadeira história só pode ser a história dos Estados. ${ }^{6}$ A teoria crítica e a hermenêutica compartilham sua origem no idealismo alemão. A teoria crítica de Kant foi construída sobre uma premissa ambígua, expressa no próprio título da Crítica da razão pura. Kant nunca explicou o genitivo ambíguo: é a razão que critica, mas com que autorização? É a razão sendo criticada, mas por quem ou pelo quê? Ou é a pretensão de pureza que está em jogo? Mas por que então admitir a razão prática? A Crítica de Kant pode alegar que mostra as condições de possibilidade da experiência ou as condições de possibilidade do conhecimento - ou ambas, como Hegel observou, tornando-se uma ontologia. Mas então, pergunta Hegel na Lógica, com o que a filosofia deve começar? Disto decorre que a questão dos fundamentos e a questão das origens implicam-se mutuamente. O resultado exclui, aparentemente, a prática política. ${ }^{7}$ No fim da Filosofia do direito, o Estado hegeliano dissolve-se no fluxo da história, que é "a Corte do Juízo Final". Exit Hegel, entra Marx.

A teoria crítica da década de 1930 era simplesmente um codinome para o marxismo. A aula inaugural de Horkheimer como diretor do Instituto de Pesquisa Social de Frankfurt, em 1931, "A situação atual da filosofia social e as tarefas de um Instituto de Pesquisa Social", explica o nascimento da filosofia social a partir do idealismo alemão, sem mencionar Marx. Entretanto, sua definição das "tarefas" da pesquisa social é perfeitamente ortodoxa ${ }^{8}$ (Horkheimer, 1972, p. 33-46). Marx não se preocupou com origens ou fundamentos. Sua tese de doutorado aceitava a realização hegeliana da filosofia como filosofia; a tarefa seguinte era "tornar mundana" esta filosofia realizada. Dois anos mais tarde, Marx encontrou o locus ou origem da filosofia realizada na sociedade civil, no ensaio "Sobre a questão judaica", e seu agente e

6. Hegel argumenta, por exemplo, que "Povos sem Estado podem ter passado muito tempo antes de alcançar esta sua determinação. E durante esses periodos eles podem ter atingido desenvolvimento considerável em algumas dimensões". Ele continua mais explicitamente: "É o Estado que primeiro apresenta conteúclo, que é não apenas adequado à prosa da história, mas a engendra. Em vez dos mandatos apenas subjetivos do governo, suficientes para as necessidades do momento, a comunidade que se consolida e eleva à altura de um Estado requer preceitos, leis, determinações gerais e válidas para a generalidade, e produz, assim, não só urn registro, como também um interesse nos fatos e acontecimentos inteligiveis, determinados e perduráveis em seus resultados..."Hegel, 1970)

7. Esta idéia é explicitamente defendida por Hegel, nos tons resignados de seu "Prefácio", em Filosofia do Direito; segundo o qual a filosofia pode apenas pintar cinza sobre cinza após o fato, quando a "coruja de Minerva" já levantou vôo. Para um argumento teórico que estabelece esta afirmação do ponto de vista da teoria crítica, ver Jürgen Habermas, "Hegel's critique of the French Revolution", em Teoria e prática.

8. A pesquisa proposta para o Instituto pergunta por que a classe operária não cumpriu a função que lhe era designada. As diferentes condições econômicas, psicológicas, legais e religiosas do capitalismo moderno devem ser examinadas empiricamente e integradas teoricamente por meio da renovação daquela "filosofia social", cuja fundamentação inadequada no idealismo alemão será completada pelo equivalente de um marxismo moderno. Em lugar algum a aula põe em dúvida a adequação do modo marxista de colocar as questões. Ela põe em dúvida apenas as soluções do século XIX fornecidas pelo marxismo ortodoxo. 
fundamento no proletariado em "Para a crítica da Filosofia do direito de Hegel". Quase um século mais tarde, a tomada do poder pelo fascismo e a experiência russa tornaram difícil aceitar tanto o locus, quanto o agente postulados por Marx. Sem a garantia de fundamentação do marxismo - quer como práxis proletária, quer como lógica da necessidade histórica ou econômica articulada na sociedade civil - a teoria crítica encontra-se na mesma posição que a hermenêutica moderna. Ela preserva do marxismo uma teoria da imanência da crise na sociedade capitalista; porém, suas escolhas políticas não podem ser justificadas pela necessidade material ou teórica. $O$ resultado é a tendência a amalgamar a pesquisa empírica com afirmações metafísicas, num esforço vão de invocar um novo "sujeito revolucionário" sob a forma de uma nova classe operária, de uma ampla frente dos oprimidos ou talvez do Terceiro Mundo ou da periferia. Qualquer desses esforços está condenado ao fracasso e isto por razões teóricas. A crise, em teoria, encontra-se "sempre já" presente, mas a solução prático-política nunca está garantida. A teoria crítica não está em melhor situação que a phronesis, admitida por Gadamer, com base numa solidariedade comunitária não demonstrável, mas pressuposta.

\section{A política da teoria}

Em seus ensaios de fundamentação dos anos $30^{9}$ (Horkheimer, 1937, p. 245-92; Horkheimer \& Marcuse, 1937, p. 634; Marcuse, 1968b, p. 135), Horkheimer e Marcuse procuram explicar não apenas as "condições de possibilidade" de sua teoria crítica, mas também as condições de sua necessidade. Esta exigência filosófica, tanto de fundamentação objetiva, quanto de origem subjetiva, significa que a busca "hermenêutica" de compreensão é incorporada juntamente com a preocupação "revolucionária" de que "não se trata de interpretar ... mas de transformar" o mundo. Este duplo imperativo evidencia o sentido em que, filosoficamente, Marx vai além da tradição ontológica do quid juris da filosofia transcendental. Embora Horkheimer tenha consciência desta exigência filosófica, é incapaz de satisfazê-la. Por exemplo, a sua segunda contribuição se encaminha para uma conclusão quase patética:

Embora seus conceitos, enraizados em movimentos sociais, hoje pareçam vãos, uma vez que nada há por trás deles a não ser seus inimigos a persegui-los, a verdade entretanto emergirá - pois a meta de uma sociedade racional, que hoje parece existir apenas na imaginação, encontra-se necessariamente em cada ser humano. (Horkheimer, 1937, p. 630)

9. Max Horkheimer, "Traditionelle und Kritische Theorie", Zeitschrift für Sozialforschung, 6, 1937 p. 245-92; Max Horkheimer e Herbert Marcuse, "Philosophie und Kritische Theorie", Zeitschrift für Sozialforschung, 6, 1937. p. 624-31 (Horkheimer), p. 631-47 (Marcuse). A contribuição de Marcuse para o ensaio foi traduzida como "Philosophy and critical theory", em Negations, tradução de Jeremy J. Shapiro. 
O único fundamento para esta fé no poder humano de resistir é sociológico. Horkheimer fala de um "juízo existencial" baseado na diferença entre juízos categóricos do feudalismo estável e juízos hipotéticos ou disjuntivos do capitalismo modernizador. Esta tentativa de fundar a necessidade em condições materiais externas é um dos critérios freqüentemente enfatizados que definem uma teoria como "tradicional". Ela corresponde ao outro critério mais importante da teoria tradicional, seu subjetivismo "cartesiano"10 (Marcuse, 1968a, p. 50). Isso poderia ser melhor feito... hermeneuticamente!

Enquanto Horkheimer falava de teoria social, Marcuse iniciava argumentando a partir da imbricação da filosofia com a própria definição de humanidade.

A filosofia queria investigar os fundamentos últimos e mais gerais do ser. Sob o nome de razão concebeu a idéia de um ser autêntico em que fossem reconciliadas todas as antíteses fundamentais (entre sujeito e objeto, essência e aparência, pensamento e ser). A esta idéia estava vinculada a conviç̧ão de que aquilo que existe não é imediatamente racional, mas precisa ser trazido à razão. A razão deve representar a suprema potencialidade do homem e da existência. Ambas vão juntas. (1968b, p. 135-6)

Enquanto este "idealismo" designa a natureza inerentemente crítica da filosofia, ele não transforma a própria filosofia em teoria social, e muito menos em teoria política. A realização da razão não é tarefa da própria filosofia. O marxismo esperava que o proletariado realizasse esta tarefa que aniquilaria (ou aufheben) a filosofia. Quando essa expectativa foi frustrada, a natureza da filosofia como crítica foi reafirmada. Isto fundamenta a possibilidade subjetiva da crítica filosófica; sua necessidade objetiva continua carecendo de demonstração.

A filosofia crítica sem o proletariado precisa desenvolver uma técnica específica que combine a crítica desmistificadora com a crítica positiva. Marcuse escreveu "O conceito de essência" porque "tantas lutas e desejos reais dos homens dirigiram-se para a procura metafísica de uma última unidade, verdade e universalidade do ser", pois a análise de tais conceitos revela concretamente a "fantasia" e o "desejo" de "felicidade material" que anima a humanidade. Assim, por exemplo, Marcuse pergunta por que Descartes combina sua filosofia mecanística, sua geometria analítica e o tratado sobre máquinas com uma filosofia baseada no ego cogito. Marcuse não interpreta isto como o "pecado original" do subjetivismo e dualismo abstratos da filosofia moderna. Descartes procurava preservar um domínio de liberdade e autonomia humanas diante do mundo externo mecânico-racional. A famosa advertência de que se deve conquistar antes a si mesmo que à fortuna não é o abandono da liberdade, mas a tentativa paradoxal de preservá-la. Analogamente, o que Marcuse analisa como o "Caráter afirmativo da cultura" não é apenas uma fuga da dura realidade. A cultura

10. A interpretação que Marcuse faz de Descartes, assim como a apresentação que Marx faz de Epicuro, em sua tese de doutorado, vê uma implicação diferente desse subjetivismo. O argumento de Horkheimer tem a ver com a metodologia das ciências sociais, enquanto a preocupação de Marcuse é fundamentar uma teoria crítica que não pode mais apelar para o proletariado. 
contém a promesse de bonheur stendhaliana que preserva o sonho-real e a fantasia existencial de liberdade, mesmo quando as condições materiais não permitem sua realização. O objetivo desta filosofia crítica é fornecer uma demonstração "hermenêutica" da fantasia e do "juízo existencial" de Horkheimer, mostrando como a imbricação da filosofia no mundo humano a torna uma força material.

A dificuldade desta solução é que, como o proletariado ou o Espírito hegeliano, ela permanece nos limites de uma "filosofia do sujeito". Não há demonstração da necessária receptividade do mundo externo ao veredicto do "juízo existencial" e da fantasia, assim como Kant pode ser acusado de incompletude na Dedução Transcendental da primeira Crítica, pois não mostra por que a multiplicidade sensível deveria de fato ser receptiva à imposição das categorias do entendimento ${ }^{11}$ (Schrader, 1953/1954, p. 204-35; Howard, 1985b, cap. 5). A pressuposição de Hegel sobre a racionalidade do presente pelo menos tentava satisfazer este imperativo. O Capital, de Marx, ou a lógica da "alienação", fornecia a demonstração concreta daquilo que Hegel e Kant podiam apenas postular. O passo seguinte foi sugerido em 1923 por Histónia e consciência de classe, de Lukács. A lógica da alienação, ou a lógica da mercadoria, com a qual Marx introduz o caráter "fetichista" do capitalismo, explica o que Lukács descreve como "segunda natureza". Porém Lukács podia ainda apelar para o proletariado com consciência de classe. A teoria crítica tenta transformar a "crítica da economia política" de Marx numa "crítica da razão instrumental". A "falsa consciência" expressa a estrutura do mundo moderno na qual o sujeito aparentemente autônomo e afirmativo transforma-se no Verstand analítico, descrito por Sartre (1960) como uma "atividade passiva", cujas relações sociais são as da "serialidade" impotente, ou o sujeito passivo receptivo, escondendo sua dependência na cultura ilusória afirmativa, que substitui sonhos por felicidade. A análise do mundo moderno, tal como formado pela razão instrumental, pretende superar o dualismo que vicia a filosofia do sujeito; dado que a filosofia e a realidade social têm a mesma estrutura, a teoria crítica reivindica tanto a necessidade subjetiva quanto a objetiva.

\section{A ausente teoria do político}

A crítica da razão instrumental baseia-se num paradoxo significativo. Como filosofia, a teoria crítica era capaz de explicar as condições de sua própria possibilidade; entretanto, era incapaz de demonstrar sua própria necessidade. A tentativa de resolver esta dificuldade, mostrando a receptividade do mundo aos veredictos da teoria, exigia a transição para a teoria crítica enquanto teoria social, seguida pela análise da sociedade moderna enquanto dominada pelo princípio da razão instrumen-

11. Cf. a brilhante argumentação de Schrader (1953/1954). Desenvolvi esta argumentação num contexto mais amplo em meu From Marx to Kant, 1985b; todo o capitulo é dedicado a "The logic of receptivity". 
tal. Deixando de lado as dificuldades imanentes desta proposta, ${ }^{12}$ ela fracassa pela razão simetricamente inversa: é incapaz de explicar as condições de possibilidade da filosofia crítica, a partir da qual toda a busca começou! (Habermas, 1984, p. 339-403) As conseqüências práticas deste círculo de paradoxos emergem inteiramente em One dimensional man, de Herbert Marcuse, que teve de recorrer a noções como as de uma física qualitativa, a revolta dos marginais, a Grande Recusa. A mudança para a crítica da razão instrumental foi poderosa demais; destruiu a questão da qual tinha emergido (Marcuse, 1964).

A postura radical de Marcuse foi o resultado de sua violação de uma das premissas cardeais da teoria crítica. Se a sociedade unidimensional fosse a totalidade, não haveria lugar a partir do qual esta totalidade pudesse ser criticada, e nenhum fulcro que permitisse seu deslocamento. Como acontece com o aforismo de Adorno, "o todo é o não-verdadeiro", isto assume a validade da teoria da razão instrumental; suas dificuldades sugerem problemas para esta teoria. A busca de um ponto arquimediano faz uma pressuposição ilícita. Ela introduz uma externalidade, algo ou algum lugar livre do sortilégio da razão instrumental ou unidimensional. Isto reintroduz a filosofia do sujeito. Ela desconsidera o conceito de totalidade que fundamentava a tentativa de Lukács de transcender as conseqüências teóricas e práticas da reificação. O marxismo hegeliano de Lukács, entretanto, pressupunha que o proletariado como o sujeito-objeto representasse a moderna totalidade.

Marcuse reconhece que o ponto de vista da totalidade tem que ser reintroduzido. A análise da razão instrumental descreve um atomismo de indivíduos abstratos que se esforçam por manter sua mera existência. O resultado é um processo de reprodução social cada vez mais incoerente e sempre em crise. Na medida em que o todo se torna mais irracional, a racionalidade é atirada para fora e para os que estão de fora, recusando a se submeter. Mas se a totalidade é verdadeiramente total, os que estão de fora estão dentro, e são necessários para manter o sistema em funcionamento, mediante o que Paul Piccone chama de a "dialética da negatividade". ${ }^{13}$ Ou a reificação instrumental é total, e neste caso a crítica é quando muito imanente e, em última análise, afirmativa;

12. Jürgen Habermas apontou os problemas mais importantes desta proposta. Ver o capitulo final, v. 1: Reason and the rationalization of society, 1984, p. 339-403. Para resumir o argumento de Habermas, não é possivel reduzir uma totalidade social a uma única forma de razão. A razão comunicativa (e emancipadora) deve sempre funcionar ao lado da razão instrumental, caso contrário a sociedade será fragmentada pela força centrífuga dos átomos individuais, procurando autopreservar-se ao custo da destruição dos mecanismos de reprodução social.

13. Paul Piccone defendeu esta posição em numerosos ensaios na revista Telos, da qual é o editor. Suas conseqüências políticas podem ser bem problemáticas, como por exemplo a afirmação de que o movimento feminista é simplesmente necessário para a reprodução ampliada de uma sociedade capitalista. Duas outras posições são possiveis no quadro dos objetivos politicos da teoria crítica. Na linha de Walter Benjamin ou Theodor Adorno, poder-se-ia tentar recuperar a sugestão da totalidade suprimida mediante a iluminação de uma crítica mimeticamente fundamentada, quer na arte, quer nas estruturas do quotidiano. Ou, na linha de Ernst Bloch, poder-se-ia propor um tipo de "hermenêutica antecipatória", a qual desenvolve a futuridade imanente, recoberta pela hermenêutica tradicional em virtude de sua orientação clássica. A respeito da primeira alternativa, ver Habermas, The theory of communicative action. Boston: Beacon, 1984. p. 339-403; a respeito da segunda, ver Burghardt Schmidt, Ernst Bloch. Stuttgart: G. B. Metzler Verlag., 1985. 
su a crítica é externa à totalidade criticada e, neste caso, não há garantia de que os resultados da crítica sejam recebidos pelos destinatários pretendidos. No primeiro caso, a possibilidade da teoria crítica exclui os resultados políticos pretendidos; no outro, os resultados políticos pretendidos não podem ser teoricamente fundamentados.

A fonte do dilema é a concepção demasiado estreita de sociedade civil, que a teoria crítica herdou de Marx. Hegel sabia que as estruturas da sociedade civil moderna põem um problema a ser resolvido no plano do Estado político. Marx considerou este problema, uma solução. Identificando a sociedade civil moderna com a sociedade capitalista, Marx desenvolveu uma teoria da economia política que mostrava por que a sociedade capitalista cria as condições subjetivas e objetivas da possibilidade de sua própria superação. Entretanto, Marx não demonstrou a necessidade de que essa possibilidade fosse realizada. A conseqüência teórica é extraída na primeira sentença da Dialética negativa, de Adorno (1973, p. 3): "A filosofia, que outrora parecia obsoleta, permanece viva porque o momento de sua realização foi perdido." ${ }^{14}$ A conseqüência política não é necessariamente o pessimismo da Dialética do Iluminismo, de Horkheimer e Adorno.

Uma concepção de sociedade civil moderna que não a identifique com a economia capitalista permite reintroduzir o ponto de vista da totalidade. Horkheimer e Adorno tratam o Iluminismo do ponto de vista de uma filosofia do sujeito. A conceptualização do Iluminismo como político já fora sugerida por Kant, para quem a criação de uma sociedade civil legal era o problema da modernidade. ${ }^{15}$ A solução de Kant gira em torno daquilo que historiadores, conscientes do paradoxo, chamam de "despotismo esclarecido". O círculo é familiar, mas não é hermenêutico; é político. A identificação das sociedades modernas com formações econômicas capitalistas (ou socialistas) é equivocada. A questão clássica da Boa Vida na Cidade não desapareceu. Pelo contrário, a modernidade a fez mais candente ao roubar da sociedade as suas instituições políticas tradicionais. Voltar-se para a economia, para a razão subjetiva ou para a razão instrumental objetiva obscurece esse fato fundamental.

\section{Hermenêutica e teoria crítica como metodologia}

A necessidade de fundamentação tanto subjetiva quanto objetiva, para a filosofia moderna, resulta numa dialética paradoxal, na qual uma ou outra, mas não ambas as

14. A reconstrução feita por Habermas da divida filosófica de Marx para com o idealismo alemão expressa esse problema ao referir-se à necessidade de um "momento fichteano": uma vez que o eu é ele próprio apenas no ato de se relacionar com o mundo, deve haver um momento de intersubjetividade que transcende a filosofia do sujeito do "eu penso" kantiano, unifica e faz minhas as minhas representações. Este momento fichteano é traduzido, na reconstrução feita por Marx sobre a sociedade civil capitalista, como o fenômeno da consciência de classe.

15. Isto é mais explicitamente formulado nas teses de Kant sobre "A idéia de história de um ponto de vista cosmopolita". Para uma interpretação de Kant com base na perspectiva a que só posso fazer aqui uma breve referência, ver Howard, 1985a, p. 79-98; 1985b. 
exigências podem ser satisfeitas. Sem uma demonstração das condições de possibilidade da filosofia, a aventura perde a sua marca racional. A modernidade introduz a dúvida reflexiva na filosofia, impelindo-a para o seu pólo subjetivo. Quando a dúvida se torna angústia, a filosofia procura uma âncora objetiva no mundo positivo. Com isso, ela sacrifica o seu eu para se preservar. A outra opção é a "filosofia da identidade" ontológica que subsume a particularidade do mundo sob a legalidade da razão filosófica. O monismo resultante desvia-se em direção ao solipsismo quando evita a esquizofrenia. Esta estrutura paradoxal é o resultado de uma filosofia da subjetividade que não pode fundamentar-se sem perder o mundo, ou fundamentar o mundo sem perder-se a si mesma.

Se a sociedade moderna é concebida como política, a disputa entre a teoria crítica de Bernstein e a hermenêutica de Gadamer pode ser resolvida mostrando-se que cada uma é correta - mas pelas razões erradas. A imanência do político como uma questão para a sociedade moderna significa que a insistência de Gadamer na possibilidade do juízo político e da phronesis prática é justificada. A dificuldade, entretanto, é mostrar quando e como esta phronesis funciona. Isto exige uma teoria daqueles particulares que tornam necessária a reflexão política; e exige uma teoria do juízo que evite a subsunção pela qual a "filosofia da identidade" reduz a alteridade à mera aparência. Eis onde entra a teoria crítica, seguindo o modelo sugerido pela relação entre a Dialética negativa de Adorno e sua teoria estética. O "juízo existencial", a mimesis e a "fantasia" são fundamentadas na imanência da questão política no interior do moderno. Este é apenas o primeiro passo. Os objetivos que Bernstein e Horkheimer postulam como telos ou totalidade, que dirigem a teoria crítica, não poderiam ser fundamentados em virtude da tendência marxista em identificar a sociedade civil com a forma econômica capitalista, ignorando a questão política da fundamentação teórica e institucional do estar-junto da sociedade. Esta questão emerge quando eventos ou instituições particulares liberam energias práticas cuja repressão constitui injustiça social. O resultado é que a possibilidade é completada pela necessidade e a particularidade é completada pela totalidade, sem amálgama ou separação irreparável.

A hermenêutica explica as condições de receptividade que fundamentam a necessidade de asserções particulares, cuja possibilidade é apontada pela teoria crítica. A teoria crítica permanece como o pólo político cuja tarefa é a articulação da particularidade; a hermenêutica fornece o complemento filosófico, cuja universalidade garante que esta política seja fundamentada. A sua relação é portanto uma relação de inclusão; só fica excluído o marxismo economicista - aceito pela primeira geração da teoria crítica -, o qual nega a imanência da questão política à sociedade civil. Inclusão não é identidade. Cada abordagem tem seu lugar e domínio legítimos. Esta limitação transforma a natureza, tanto da hermenêutica quanto da teoria crítica. Nenhuma delas pode fazer as alegações totalizantes que sua formulação filosófica sugere. Em vez disso, cada uma se torna um momento metodológico no interior de uma teoria da modernidade que transforma a ambas. Neste contexto, a crítica política 
de Bernstein a Gadamer é perfeitamente correta. Gadamer é um naï político...mas não é necessário tratá-lo como um filósofo político. A filosofia política de uma teoria crítica não-economicista mostra à hermenêutica os limites e o lugar que lhe são próprios, assim como a hermenêutica em relação à teoria crítica. Se esta reconstrução de uma teoria crítica contemporânea é compatível com a variante proposta pela suma da segunda geração, a Teoria da ação comunicativa de Habermas é um tópico que sem dúvida retornará nas discussões em curso ${ }^{16}$ (Howard, 1987).

HOWARD, D. Hermeneutics and critical theory: enlightenment as political. Trans/Form/Ação, São Paulo, v. 17, p. 51-61, 1994.

- ABSTRACT: This paper analyses Gadamer's hermeneutics and the critical theory of Horkheimer and Marcuse. It tries to show that, if modern society is conceived as political, then it is possible to elaborate a theory of modernity where hermeneutics and critical theory, instead of opposing, complement each other.

- KEYWORDS: Hermeneutics; critical theory; politics; civil society; modernity.

\section{Referências bibliográficas}

1 ADORNO, T. W. Negative dialectics. Trad. E. B. Ashton. New York: The Seabury, 1973.

2 BERNSTEIN, R. Beyond objectivism and relativism: (Science, hermeneutics and praxis.) Philadelphia: University of Pensylvania, 1983.

3 GADAMER, H. G. Wahrheit und Methode: Grundzüge einer philosophischen Hermeneutik. Tubingen: J. C. B. Mohr, 1975.

4 HABERMAS, J. Hegel's critique of the French Revolution. In: The theory of communicative action. Trad. T. McCarthy. Boston: Beacon, 1984. v. 1, p. 339-403.

5 HEGEL, G. W. F. Philosophy of night. Trad. T. M. Knox. Oxford: University Press, 1967. 6 Vorlesungen über die Philosophie der Geschichte. Frankfurt am Main: Suhrkamp, 1970. (Werke, 12).

7 HORKHEIMER, M. Traditionelle und kritische Theorie. Zeitschnift für Sozialforschung, v. 6, p. 245-292, 1937.

8 Sozialphilosophische Studien. Frankfurt: Fischer, 1972.

9. HORKHEIMER, M., MARCUSE, H. Philosophie und kritische Theorie. Zeitschnift für Sozialforschung, v. 6, p. 624-47, 1937.

10 HOWARD, D. Kant's system and (its) politics. Man and world, v. 18, p. 79-98, 1985a.

11 The logic of receptivity. In: From Marx to Kant. Albany: Suny, 1985b. cap. 5.

12 The Marxian legacy. Minneapolis: University of Minnesota Press, 1987.

13 MARCUSE, H. One dimensional man. Boston: Beacon, 1964.

16. Ver o "Posfácio" à segunda edição de The Marxian legacy, para uma discussão detalhada cleste problema. 
14 MARCUSE, $\mathrm{H}$. The concept of essence. In: Negations. Trad. J. J. Shapiro. Boston: Beacon, 1968a.

15 Philosophy and critical theory. In: Negations. Trad. J. J. Shapiro. Boston: Beacon, 1968b.

16 SARTRE, J. P. Critique de la raison dialectique. Paris: Gallimard, 1960.

17 SCHMIDT, B. Ernst Bloch. Stuttgart: G. B. Metzler, 1985.

18 SCHRADER, G. The status of teleological judgement in the critical philosophy. Kantstudien, v. 45, p. 204-35, 1953-1954. 